\title{
Hes1 negatively regulates neurogenesis in the adult mouse dentate gyrus following traumatic brain injury
}

\author{
RONG YAN ${ }^{1-3^{*}}$, LIN ZHANG $^{1-3^{*}}$, MENGQI LI ${ }^{3,4^{*}}$, XIAOZHI LIU ${ }^{2}$, XINYU YANG ${ }^{3,4}$ and LEI CHEN ${ }^{1}$ \\ ${ }^{1}$ Department of Neurosurgery; ${ }^{2}$ Central Laboratory, The Fifth Central Hospital of Tianjin, Tianjin 300450; \\ ${ }^{3}$ Laboratory of Cerebrovascular Disease, Tianjin Neurological Institute, Key Laboratory of Post-trauma Neuro-repair \\ and Regeneration in Central Nervous System, Ministry of Education, Tianjin Key Laboratory of Injuries, \\ Variations and Regeneration of Nervous System; ${ }^{4}$ Department of Neurosurgery, Tianjin Medical University General Hospital, \\ Tianjin 300052, P.R. China
}

Received February 22, 2018; Accepted June 1, 2018

DOI: $10.3892 /$ etm.2018.6450

\begin{abstract}
Traumatic brain injury (TBI) results in the activation of neurogenesis, but it also triggers multiple cell signaling pathways that may lead to either cell damage or cell survival. In general, the repair processes following TBI are characterized by a failure to replenish the neuronal population entirely. To date, the factors that determine whether neurogenesis will be sufficient for the replacement of lost neurons following brain injury are not fully understood. Decreased activation of Hes1, a transcriptional repressor, is observed as neural differentiation proceeds, and this gene continues to play a role in the quiescence of stem cells into adulthood. Since Hesl is negatively correlated with neurogenesis in adult rodents, the present study investigated whether this gene inhibits TBI-induced neurogenesis by use of adenovirus-mediated gene transfer to upregulate Hesl expression in the dentate
\end{abstract}

Correspondence to: Dr Lei Chen, Department of Neurosurgery, The Fifth Central Hospital of Tianjin, 41 Zhejiang Road, Binhai New Area, Tianjin 300450, P.R. China

E-mail: chenlei1130@163.com

Dr Xinyu Yang, Department of Neurosurgery, Tianjin Medical University General Hospital, 154 Anshan Road, Heping, Tianjin 300052, P.R. China

E-mail: chnxyyang@163.com

*Contributed equally

Abbreviations: TBI, traumatic brain injury; DG, dentate gyrus; SGZ, subgranular zone; Ad-Hes1, adenovirus-Hes1; BrdU, bromodeoxyuridine; DCX, doublecortin; bHLH, basic helix-loop-helix; NSCs, neural stem cells; CNS, central nervous system; Ad5, adenovirus serotype 5; EGFP, enhanced green fluorescent protein; mCMV, murine cytomegalovirus; PBS, phosphate-buffered saline; PVDF, polyvinylidene difluoride

Key words: Hes1, traumatic brain injury, gene transfer, dentate gyrus, adult neurogenesis gyrus (DG) in a mouse model of TBI. Western blot analysis and immunofluorescent staining revealed increased Hes1 protein expression in the subgranular zone (SGZ) of the DG following adenovirus-Hes1 (Ad-Hes1) transfection and a decreased number of bromodeoxyuridine-positive and doublecortin-positive cells in the SGZ in the transfection group following TBI. These data indicated a negative association between the expression of Hesl and adult neurogenesis following the induction of TBI. Furthermore, the present findings demonstrate the value of downregulating Hes 1 expression following TBI to promote the initiation of endogenous neurogenesis, which may be of therapeutic value for patients with brain injuries.

\section{Introduction}

Hes genes are essential effectors of the Notch pathway (1), which is an evolutionarily conserved intercellular signaling cascade critical for the maintenance of stem cells, the specification of cell fate, and cellular differentiation, proliferation and apoptosis (2). During neuronal development, Hes genes control the timing of cell differentiation and are crucial for determining the appropriate cellular size, shape and arrangement in brain structures (3). Hes genes contain a basic helix-loop-helix (bHLH) domain, an orange domain and a tetrapeptide motif. Of the bHLH genes, Hes 1 is one of the most important regulators of cell fate decisions. This gene was originally identified as a mammalian homologue of the Drosophila hairy and Enhancer of split gene (4), which negatively regulates neurogenesis in Drosophila (5). The Hes1 protein is expressed in a wide variety of tissues in both embryos and adults (6). Hesl-deficient mice exhibit premature differentiation during the development of the nervous system and, subsequently, severe neurological defects (7). By contrast, overexpression of Hesl leads to the inhibition of neurogenesis and the maintenance of neural stem cells (NSCs) (8). Thus, Hes 1 gene is essential for generation of a full diversity of cell types by maintaining NSCs until later stages. In addition, Hes 1 gene also regulates maintenance of boundaries in the developmental brain (9). Therefore, Hesl gene controls the proper timing of neurogenesis and morphogenesis. 
Notch signaling is also present in two of the prominent niches for NSCs in the adult rodent brain, the subgranular zone (SGZ) of the hippocampus and the subependymal zone of the lateral ventricles in adult mice (10). Due to the change in environment during the developmental transition from embryonic stages to adulthood, novel molecular mechanisms may be involved in adult neurogenesis. In adult diseases of the central nervous system (CNS), Notch signaling serves a critical function in specific pathological processes, including synaptic plasticity associated with learning and memory processes (11), the mechanisms underlying Alzheimer's disease (12), and inhibition of multipotent cellular differentiation during multiple sclerosis (13). These findings suggest that Notch signaling is involved in adult neurogenesis under both normal and pathological conditions.

Neurogenesis can be induced by various types of traumatic brain injury (TBI) $(14,15)$, but specific mechanisms are involved in the inhibition of proliferation and differentiation of new cells following injury. Hes 1 gene inhibits the precocious differentiation and maintenance of NSCs during development (4). Although the precise nature of Notch-Hes signaling in the adult brain remains unclear, Hesl expression promotes the quiescence of hematopoietic stem cells (16) and controls the reversibility of the quiescent state in cultured fibroblast cell lines (17). Thus, it is conceivable that Hesl genes may maintain the progenitor/NSC state throughout life even in special microenvironments, including following TBI.

The repair processes enacted following TBI are characterized by astrogliosis (18), and inflammation has been reported to inhibit neurogenesis in the brain (19). Furthermore, the redox state suppresses neurogenesis and directs the differentiation of cells towards an astroglial lineage in a Sirt1-Hes1-dependent fashion (20). The in vivo knockdown of Sirtl or Hesl genes results in a higher proportion of doublecortin-positive $[\mathrm{DCX}(+)]$ cells in mice subjected to oxidation, which indicates an increase in neurogenesis (20). Since inflammation is also associated with damage-related processes secondary to TBI, it is possible that Hesl genes are involved in the negative regulation of neurogenesis after TBI. Thus, the current study investigated the precise role of Hesl in TBI-related neurogenesis by upregulating Hes1 protein via adenovirus-mediated gene transfer in a mouse model of TBI induced by lateral fluid percussion.

\section{Materials and methods}

Animals. The present study included 60 adult male C57BL/6 mice obtained from the Laboratory Animal Center of Tianjin Medical University [Tianjin, China; certificate no. SYXK (Jin) 2016-0001]. The mice were 10 weeks old (25-30 g) and housed in cages under a 12-h light-dark cycle with free access to food and water (temperature, $17 \pm 3^{\circ} \mathrm{C}$; humidity, $50 \pm 20 \%$ ). All experimental procedures were approved by the Animal Ethics Commission of the Tianjin Fifth Central Hospital (Tianjin, China). The subjects were divided randomly into three groups: i) Sham-operated group $(n=21)$; ii) stereotactic injection of adenovirus serotype 5 (Ad5)-expressing enhanced green fluorescent protein (Ad-EGFP group; $n=21$ ); and iii) stereotactic injection of adenovirus-Hes1 (Ad-Hes1 group; $n=18$ ).
Adenoviral vectors. All viruses used in this study were based on Ad5 and were E1-deleted first-generation adenoviral vectors with further deletion in E3. Expression cassettes were inserted into the E1 region and contained the murine cytomegalovirus (mCMV) promoter, the transgene and simian virus 40 poly(A) (21). Procedures utilizing Ad-EGFP under the control of the mCMV promoter have been described previously $(22,23)$. Briefly, the virus was packaged in 293 cells (Benyuan Zhengyang Gene Technology Co., Ltd., Beijing, China), amplified using the AdMax ${ }^{\mathrm{TM}}$ virus purification kit (Benyuan Zhengyang Gene Technology Co., Ltd.) according to the manufacturer's protocol, and titrated as previously described (24).

Stereotactic injections. Adenoviral vectors with Ad-EGFP or Ad-Hes1 $\left[1 \times 10^{8} \mathrm{IU} / \mathrm{mouse}\right.$ in $2 \mu \mathrm{l}$ phosphate-buffered saline (PBS)] were injected into the dentate gyrus (DG) of the hippocampi of adult mice. Briefly, the mice were anesthetized with an intraperitoneal injection of $10 \%$ chloral hydrate $(400 \mathrm{mg} / \mathrm{kg}$ body weight) and mounted in a stereotaxic apparatus with a mouse adaptor (David Kopf Instruments, Tujunga, CA, USA). The skull was opened using a dental drill, and the adenoviral vectors $(2 \mu \mathrm{l})$ were injected into the DG (AP: $-1.9 \mathrm{~mm}$, L: $-1.2 \mathrm{~mm}$, DV: $-1.8 \mathrm{~mm}$, according to bregma) using a glass capillary with an outer diameter of $\sim 70 \mu \mathrm{m}$ mounted on a 5- $\mu 1$ Hamilton syringe (25). The needle was lowered into the brain at the site of injection, and a 2-3-min waiting period transpired prior to depression of the syringe plunger delivering the vector. The plunger was depressed in $0.5-\mu 1$ increments over $1-\mathrm{min}$ periods with a 1-min waiting period between each depression until the entire $2 \mu \mathrm{l}$ of vector had been administered. Following the final administration, a 5-min waiting period transpired before the plunger was removed to allow for dispersion of the vector. The sham-operated group was subjected to identical surgery but without injection.

Lateral fluid percussion model of TBI. On day 3 after the stereotactic injections, mice of the group subjected to bromodeoxyuridine (BrdU) immunofluorescent staining received intraperitoneal injections of BrdU $(200 \mathrm{mg} / \mathrm{kg}$ dissolved in saline to a final concentration of $20 \mathrm{mg} / \mathrm{ml}$; Sigma-Aldrich; Merck KGaA, Darmstadt, Germany) $30 \mathrm{~min}$ prior to the induction of TBI. Following BrdU injection, the mice were anesthetized via an intraperitoneal injection of $10 \%$ chloral hydrate (400 mg/kg body weight) and fixed into the stereotactic apparatus. The dorsal scalp was then exposed via a midline cut, and a 3-mm craniotomy was made on the right parietal bone $1 \mathrm{~mm}$ lateral to the sagittal suture between the lambda and bregma sutures. Luer lock fitting was cemented to the skull as described previously (26), and the mice were subjected to a lateral fluid percussion injury of $202 \pm 2 \mathrm{kPa}$ using a pre-calibrated fluid percussion injury device. Following the induction of TBI, the Luer lock fitting was removed, the wound was sutured, and the mice were returned to their cages.

Tissue preparation and immunofluorescent staining. Mice were placed under deep anesthesia and perfused with cold PBS followed by $4 \%$ paraformaldehyde solution. The brains were removed, kept in $4 \%$ paraformaldehyde for $24 \mathrm{~h}$ after fixation and immersed in $30 \%$ sucrose for $24-48 \mathrm{~h}$ at $4^{\circ} \mathrm{C}$, then frozen 
A
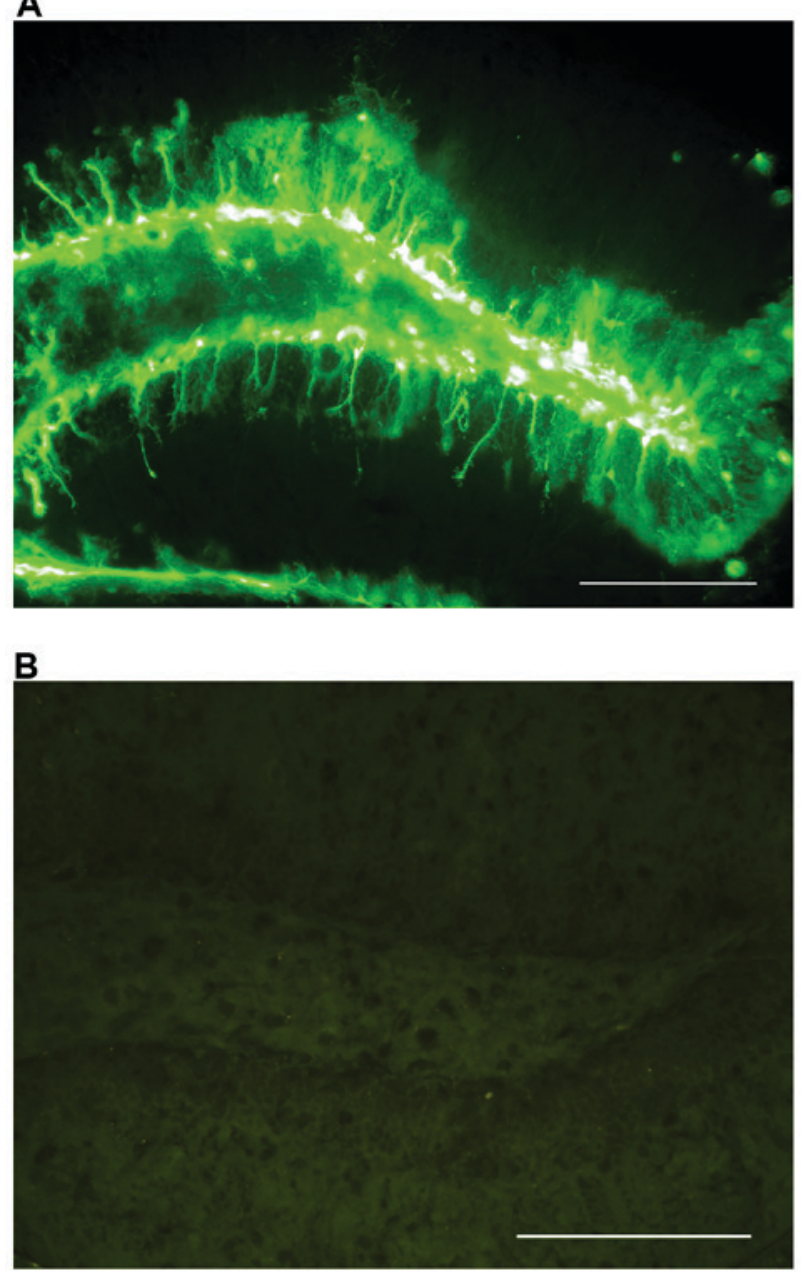

Figure 1. Expression of EGFP following adenovirus-mediated transfection in the hippocampus. (A) Staining for EGFP in the transfected mouse dentate gyrus of the ipsilateral hippocampus on day 3 following stereotactic injection of Ad-EGFP. (B) There was no expression of EGFP in the sham-operated group. $\mathrm{n}=3$. Scale bar $=200 \mu \mathrm{m}$. EGFP, enhanced green fluorescent protein; Ad-EGFP, adenovirus serotype 5 expressing EGFP.

at $-80^{\circ} \mathrm{C}$. The frozen brains were sliced in $35-\mu \mathrm{m}$-thick coronal sections through the entire hippocampus using a cryostat, and the slices were collected in 6-well plates filled with PBS. A 1-in-5 series of sections was collected from each animal and processed for immunostaining to assess the number of positively stained cells, as described previously (27). The sections were incubated in a solution of blocking medium (0.3\% Triton-X-100 and 2\% goat serum in $0.1 \mathrm{M} \mathrm{PBS}$; Abcam, Cambridge, MA, USA) for $60 \mathrm{~min}$ at $37^{\circ} \mathrm{C}$ and then with HesI (rabbit anti-Hes1; 1:200 dilution; cat. no. ab108937; Abcam), BrdU (rat anti-BrdU; 1:50 dilution; cat. no. ab6323; Abcam) or DCX (mouse anti-DCX; 1:100 dilution; cat. no. sc-271390; Santa Cruz Biotechnology, Inc, Dallas, TX, USA) primary antibodies diluted in blocking solution overnight at $4{ }^{\circ} \mathrm{C}$ on a shaker. Finally, the sections were incubated with fluorescent secondary antibodies (Alexa Fluor 555 goat anti-rabbit IgG, cat. no. 4413; Alexa Fluor 555 goat anti-mouse IgG, cat. no. 4409; and Alexa Fluor 488 goat anti-rat IgG, cat. no. 4416; all 1:1,000 dilution; all from Cell Signaling Technology, Inc, Danvers, MA, USA) diluted in 0.1 M PBS (pH 7.4) with $0.3 \%$ Triton X-100 solution for $1 \mathrm{~h}$ at $37^{\circ} \mathrm{C}$. The DNA was stained with DAPI in mounting medium for $5 \mathrm{~min}$ at $37^{\circ} \mathrm{C}$ (Santa Cruz Biotechnology, Inc.). The negative control slices for Hesl staining were subjected to an identical staining procedure without the primary antibody. All fluorescent images were acquired using a fluorescence microscope and an image capture system.

Quantification of immunofluorescence results. All analyses were performed using stereological counting methods. The immunofluorescent staining for BrdU was conducted 3 days after the TBI procedure $(n=6)$ on the hippocampal slices (bregma -1.3 to $-3.1 \mathrm{~mm}$ ) from each subject. A systematic random sampling of a 1-in-5 series of coronal sections was prepared from each brain and processed for immunofluorescence. The entire SGZ of the DG was assessed and every BrdU-positive [BrdU(+)] cell was counted and examined using a fluorescent microscope with $x 40$ objective lens. Ten sections per brain specimen from 6 mice per group were examined, and the total number of cells counted in the sections from each mouse was multiplied by 5 to estimate the total number of positive cells in the SGZ.

Western blot analysis. The subjects were sacrificed, and the ipsilateral hippocampal tissue samples were snap-frozen in liquid nitrogen immediately. The samples were homogenized in ice-cold radioimmunoprecipitation assay buffer (Beijing Solarbio Science \& Technology Co., Ltd., Beijing, China) using a sonicator $(130 \mathrm{~W} ; 35 \%)$ for $5-10 \mathrm{sec}$ at $4^{\circ} \mathrm{C}$, centrifuged at $15,520 \mathrm{x} \mathrm{g}$ for $10 \mathrm{~min}$ at $4^{\circ} \mathrm{C}$. Protein concentrations were determined by bicinchoninic acid assay (Beijing Solarbio Science \& Technology Co., Ltd.). The proteins (30 $\mu \mathrm{g} / \mathrm{lane})$ were transferred onto a polyvinylidene difluoride (PVDF) membrane (EMD Millipore, Billerica, MA, USA) following electrophoretic separation on a $10 \%$ SDS-PAGE gel. The PVDF membranes were incubated in blocking buffer (TBST containing $5 \%$ milk) for $2 \mathrm{~h}$ at room temperature and probed with primary antibodies (rabbit anti-Hes1, 1:1,000 dilution, cat. no. ab108937, Abcam; mouse anti-DCX, 1:500 dilution, cat. no. sc-271390; Santa Cruz Biotechnology, Inc.; rabbit anti-GAPDH, 1:1,000 dilution, cat. no. 5174; Cell Signaling Technology, Inc.) overnight at $4^{\circ} \mathrm{C}$. Goat anti-rabbit $(1: 2,000$ dilution; cat. no. sc-2004; Santa Cruz Biotechnology, Inc.) or goat anti-mouse (1:2,000 dilution; cat. no. sc-2005; Santa Cruz Biotechnology, Inc.) secondary antibodies conjugated to horseradish peroxidase were then applied for $2 \mathrm{~h}$ at room temperature, and the bound antibodies were detected using an enhanced chemiluminescence assay (SuperSignal ${ }^{\mathrm{TM}}$ West Pico Chemiluminescent Substrate; Thermo Fisher Scientific, Inc, Waltham, MA, USA). Changes in the levels of proteins were evaluated using ImageJ image analysis software (version, 2.0.0-rc/1.51u; National Institutes of Health, Bethesda, MD, USA).

Statistical analysis. All data are presented as the mean \pm standard error of the mean. One-way analysis of variance and post hoc Bonferroni tests were performed using SPSS (version 18.0; SPSS, Inc., Chicago, IL, USA) to compare the levels of Hes1 and DCX proteins and the number of $\mathrm{BrdU}(+)$ cells among groups. $\mathrm{P}<0.05$ was considered to indicate a statistically significant difference. 

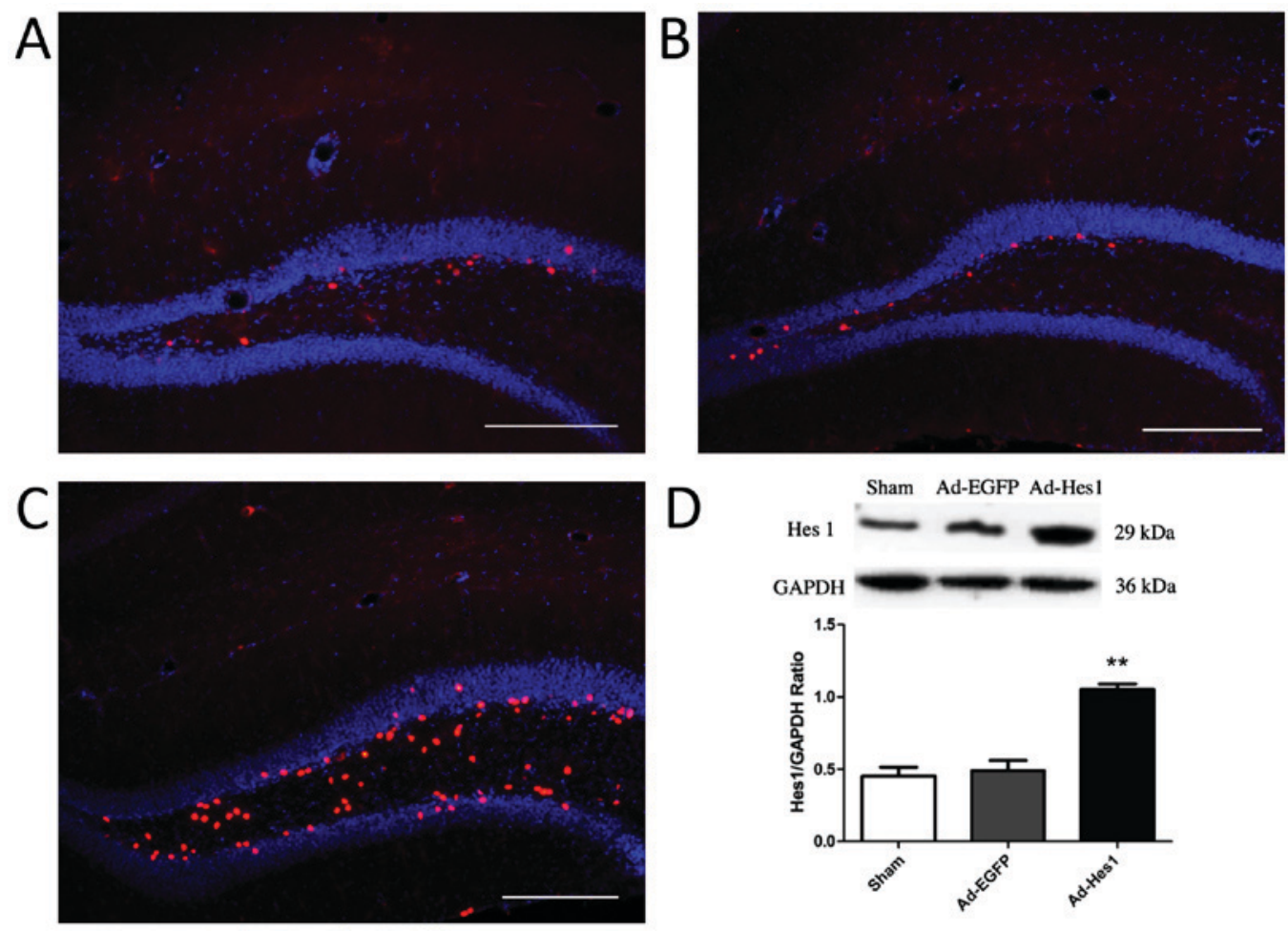

Figure 2. Expression of Hes1 following adenovirus-mediated transfection into the hippocampus. Fluorescent staining for Hes1 (red) and DAPI (blue) in the mouse dentate gyrus of the ipsilateral hippocampus on day 3 following injection in the (A) sham-operated, (B) stereotactic injection of Ad-EGFP and (C) stereotactic injection of Ad-Hes1 groups ( $\mathrm{n}=3 /$ group). Scale bar=200 $\mu \mathrm{m}$. (D) Western blot analysis for the expression of Hes1 in the ipsilateral hippocampus of the sham-operated, stereotactic injection of Ad-EGFP, and stereotactic injection of Ad-Hes1 groups. GAPDH was used as an internal control. Hes1 expression was quantified using semi-quantitative densitometry. Data are presented as the mean \pm standard error of the mean ( $n=3$ ). ${ }^{* *} \mathrm{P}<0.01$ vs. the sham-operated and stereotactic injection of Ad-EGFP groups. Ad-EGFP, adenovirus serotype 5 expressing enhanced green fluorescent protein; Ad-Hes1, adenovirus serotype 5 Hesl.

\section{Results}

Adenovirus-mediated transfection of the Hesl gene in the hippocampi of adult mice. To detect adenovirus-mediated transfection and expression of Hesl in the hippocampus, the expression of EGFP in the DG was identified first, and the expression of the Hes1 protein was then examined using immunofluorescent staining and western blot analysis. EGFP was highly expressed in the SGZ of the DG for 3 days following transfection (Fig. 1), demonstrating the effectiveness of adenovirus-mediated transfection. The expression of Hes1 was also clearly observed in the SGZ on day 3 following transfection using immunofluorescent staining (Fig. 2A-C). To further characterize the expression of Hes1, western blot analyses were performed on day 3 following transfection. Compared with the control groups, there was a significant increase in the relative expression of Hes1 in the transfection group $(\mathrm{P}<0.01$; Fig. 2D). Together, these results indicate that in vivo Ad-Hes1 transfection effectively increased Hes1 expression in the mouse hippocampus and that Hes1 is expressed primarily in the SGZ of the hippocampus.

Ad-Hesl transfection reduces the proliferation of NSCs in the DG following TBI. To confirm the association between Hesl and the proliferation of NSCs following TBI, the number of $\mathrm{BrdU}(+)$ cells on day 3 after TBI induction was quantified by immunofluorescent staining. When comparing the extent of cell proliferation among the groups, the number of $\mathrm{BrdU}(+)$ cells in the DG of mice was significantly higher in the sham-operated and Ad-EGFP groups compared with the Ad-Hes1 group $(1,515 \pm 77$ and $1,588 \pm 56$ vs. $703 \pm 58$; $\mathrm{n}=6$; $\mathrm{P}<0.001$; Fig. 3). Immunofluorescence revealed a significant reduction in the number of NSCs in the SGZ 3 days after TBI induction in the Ad-Hes1 group, indicating that Hes1 negatively regulates the proliferation of NSCs in the hippocampus after TBI.

Ad-Hesl transfection reduces the number of $D C X(+)$ immature neurons in the DG following TBI. In the present study, Hesl negatively regulated hippocampal neurogenesis following TBI. To determine whether Hesl mediates differentiation during hippocampal neurogenesis following injury in adult mice, the number of DCX(+) cells in the SGZ of the DG was measured 7 days after the induction of TBI. Immunofluorescent staining revealed a marked decrease in the number of $\mathrm{DCX}(+)$ cells in the Ad-Hes1 group compared with the sham-operated and Ad-EGFP groups (Fig. 4A-C). Similarly, western blot analysis revealed that the expression of DCX was significantly lower in the Ad-Hes1 group compared with the other groups $(\mathrm{P}<0.01$; Fig. 4D) indicating that the expression of Hes1 decreased the number of DCX(+) immature neurons in the DG. These findings suggest that Hes1 negatively regulates the survival of immature neurons in the DG following TBI and/or inhibits the differentiation of these immature neurons into granular neurons. 

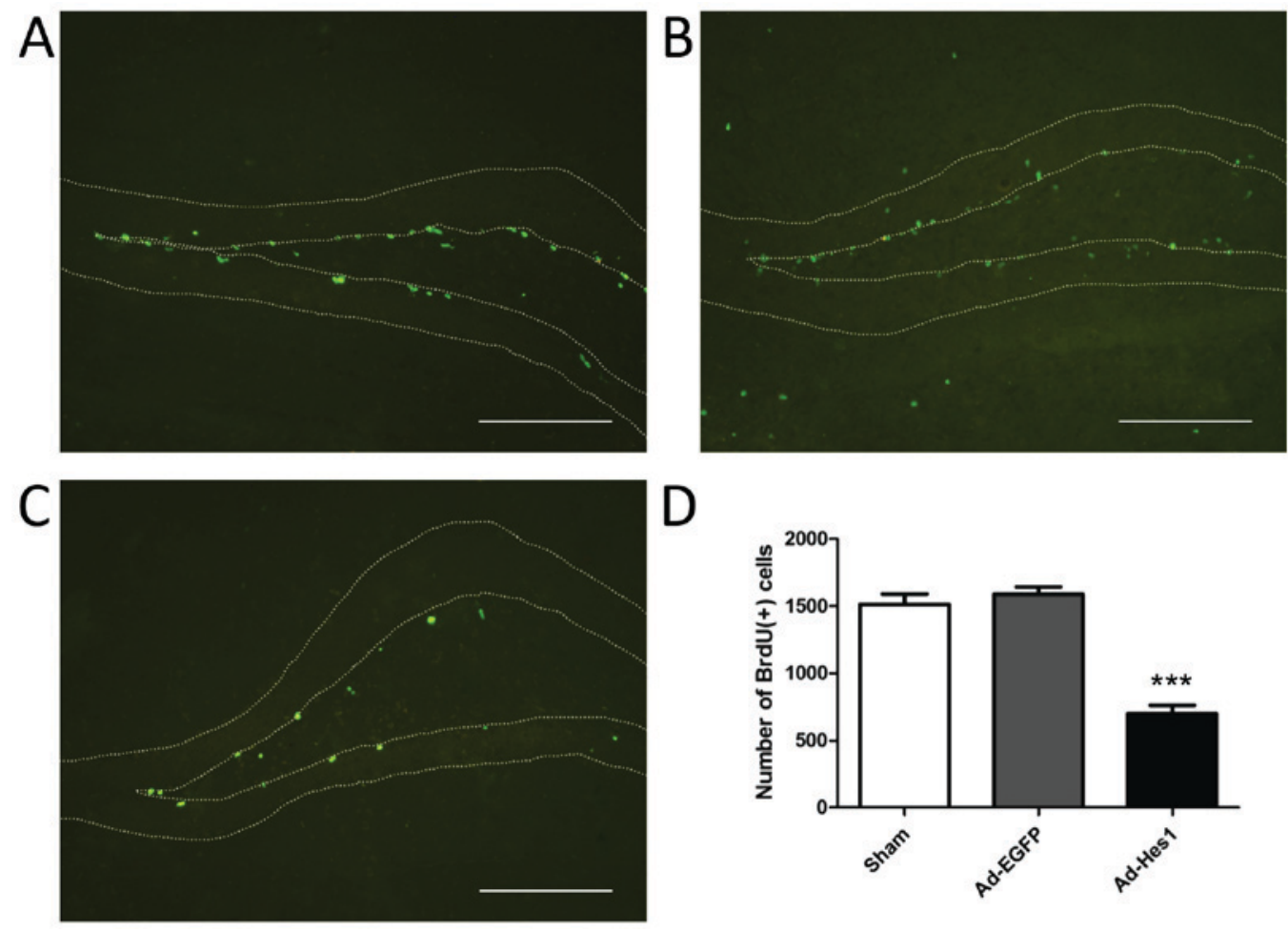

Figure 3. Proliferation of neural stem cells following TBI in each group. Fluorescent staining for BrdU (green) in the mouse dentate gyrus of the ipsilateral hippocampus on day 3 after TBI in the (A) sham-operated, (B) stereotactic injection of Ad-EGFP and (C) Ad-Hes1 groups. Scale bar=200 $\mu \mathrm{m}$. (D) Quantitative analysis of the extent of cell proliferation in the SGZ of the DG. $n=6 .{ }^{* * *} \mathrm{P}<0.001 \mathrm{vs}$. the sham-operated and stereotactic injection of Ad-EGFP groups. TBI, traumatic brain injury; BrdU, bromodeoxyuridine; Ad-EGFP, adenovirus serotype 5 expressing enhanced green fluorescent protein; Ad-Hes1, adenovirus serotype 5 Hesl.
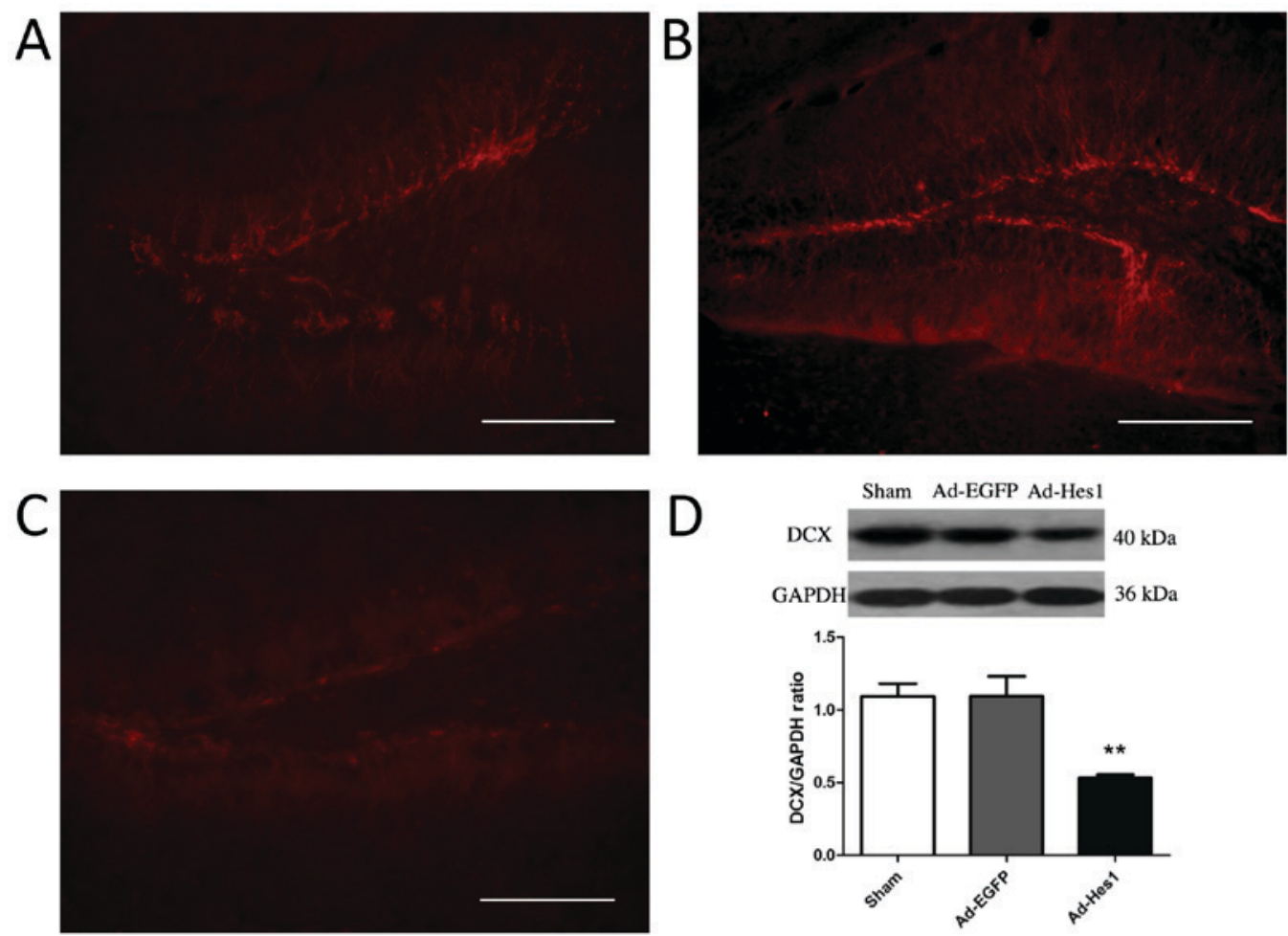

Figure 4. Expression of DCX in immature neurons of the dentate gyrus following TBI induction in each group. Fluorescent staining of DCX (red) in the mouse dentate gyrus of the ipsilateral hippocampus on day 7 after TBI in the (A) sham-operated, (B) stereotactic injection of Ad-EGFP and (C) stereotactic injection of Ad-Hes1 groups (n=3/group). Scale bar=200 $\mu \mathrm{m}$. (D) Western blot analysis of the expression of DCX in the ipsilateral hippocampus in the sham-operated, stereotactic injection of Ad-EGFP and stereotactic injection of Ad-Hes1 groups. GAPDH was used as an internal control. DCX expression was quantified using semi-quantitative densitometry. Data are presented as the means \pm standard error of the mean $(\mathrm{n}=3)$. ${ }^{* *} \mathrm{P}<0.01$ vs. the sham-operated and stereotactic injection of Ad-EGFP groups. TBI, traumatic brain injury; DCX, doublecortin; Ad-EGFP, adenovirus serotype 5 expressing enhanced green fluorescent protein; Ad-Hes1, adenovirus serotype 5 Hes1. 


\section{Discussion}

It is well established that new neurons are generated in the adult mammalian brain throughout life. Neurogenic regions in the adult CNS include the SGZ of the DG in the hippocampus and the subventricular zone (SVZ) of the lateral ventricles in the forebrain $(28,29)$, which maintain relatively quiescent states in a stable microenvironment. In a post-injury state in adult animals, progenitor cells in the SGZ are activated $(30,31)$, and this injury-induced neurogenesis is a compelling potential contributor to post-injury recovery $(14,15,32)$. In fact, the concept of replacing neurons lost following TBI is becoming a realistic treatment strategy (33). However, the ability of endogenous neurogenesis to contribute to recovery following brain injury is insufficient, and the incomplete replacement of damaged neurons may account for clinical deficits. TBI triggers multiple and distinct cell signaling pathways that may lead to either cell damage or cell survival. Thus, in order to completely restore CNS function following TBI, the negative regulators of neurogenesis should be considered as potential therapeutic targets in addition to the positive factors modulating this process. In the future, the effective downregulation of negative factors offers a novel mode of treatment for TBI.

Several signaling cascades that play roles in the maintenance of stem cells have been identified, including the Notch-Hes pathway $(34,35)$. Hes genes appear to be expressed in stem cell zones during adulthood, and the expression of Hes1 is crucial for the maintenance of quiescent hematopoietic stem cells (16). Thus, Hes1 may play a role in the maintenance of the progenitor/NSC state in the adult CNS. In the present study, the adenovirus-mediated gene transfer of Hesl into the SGZ of adult mice effectively upregulated the expression of Hes1 following brain injury.

Viral vector-mediated gene delivery is an attractive method for introducing genes into the brain. Adenoviral vectors have a cloning capacity of several kilobases, and adenoviral DNA does not integrate into the host genome, thereby avoiding the risk for mutagenesis associated with retroviral vectors (36). Most recombinant adenoviral vectors use viral promoters, such as the CMV promoters, which induce high levels of transcription. Because the injection of adenoviral vectors into the CNS triggers an acute dose-dependent but relatively mild inflammatory response, characterized by the infiltration of immune cells from the circulatory system $(37,38,21)$, the vectors may be scavenged rapidly, and transgene expression cannot be maintained for an extended period of time. This acute inflammatory response is dose-dependent with a particular threshold $\left(1 \times 10^{8} \mathrm{IU}\right)$ when injected into the brain (39). Data from our laboratory have demonstrated that injection of Ad-mCMV expressing EGFP at a dose of $1 \times 10^{8}$ IU lasts $\geq 2$ months in the hippocampus (40). In the present study, Ad-mCMV with Hesl was injected at a dose of $1 \times 10^{8} \mathrm{IU}$, which ensured a high level of Hes1 expression in the hippocampus. Immunofluorescent staining and western blot analyses demonstrated stable expression of Hesl following adenoviral-mediated transfection. Furthermore, this indicated that the use of specific viral promoters may drive long-term, cell-specific gene expression in exclusive cell populations.
In the present study, an adenoviral vector carrying mCMV promoter, was constructed. Transgene expression mediated by Ad-mCMV was primarily observed in the SGZ and SVZ, with NSCs in the SGZ transduced preferentially. This characteristic is suitable for the study of neurogenesis in the adult hippocampus. Since Hes1 is primarily expressed in the neurogenic regions (SGZ and SVZ) of the adult brain, its upregulation in these regions using Ad-mCMV-mediated gene transfer is appropriate to investigate adult neurogenesis following TBI.

In the current study, Ad-mCMV-Hesl was transferred into the hippocampus of an adult mouse, and this upregulated the expression of Hes1 in the SGZ, which reduced the number of $\mathrm{BrdU}(+)$ and $\mathrm{DCX}(+)$ cells. DCX is a marker of immature neurons, observed in the DG during the early differentiation stages of adult neurogenesis (41). DCX-expressing cells likely contribute to stable neurogenesis in the DG (42). BrdU is a marker of DNA synthesis and thus prominent in proliferating cells. However, BrdU labeling is also detected in cells undergoing DNA repair and those aborting cell cycle re-entry as a prelude to apoptosis (43). DCX and BrdU indicate activation of NSCs in the SGZ following TBI, and in the present study, the upregulation of Hes1 expression inhibited the proliferation of progenitor/stem cells and the survival of immature neurons. These results indicate that Hesl negatively regulated adult neurogenesis in the SGZ following TBI. It is possible that the upregulation of Hes1 following TBI inhibited the transformation of stem cells from progenitor cells to immature neurons.

The present study provides strong evidence supporting the role of Hesl in the negative regulation of specific neurogenic processes in the adult brain following TBI. This type of negative regulation inhibits positive neurogenesis and interferes with the complete recovery of neural function following brain injury, and thus, it is important to continue exploring the mechanisms underlying the action of Hesl to enhance endogenous neurogenesis. The present findings suggest that downregulation of Hes1 expression, due to its therapeutic potential, may be an effective strategy for the treatment of TBI.

\section{Acknowledgements}

Not applicable.

\section{Funding}

This study was supported by grants from the National Natural Science Foundation of China (grant no. 81501073), the Natural Science Foundation of Binhai New Area in Tianjin (grant no. 2015BWKY007), the Science and Technology Foundation of Tianjin (grant no. 2015KZ016), the National Natural Science Foundation of China (grant no. 81571144) and the Natural Science Foundation of Tianjin City (grant no. 16JCZDJC35700).

\section{Availability of data and materials}

All data generated or analyzed during this study are included in this published article. 


\section{Authors' contributions}

RY, LZ and ML conducted experiment and wrote the manuscript; XL analyzed the data; XY and LC designed the study and revised the manuscript. All authors read and approved the final manuscript.

\section{Ethics approval and consent to participate}

Ethical approval for the study was granted from the Animal Ethics Commission of the Tianjin Fifth Central Hospital (Tianjin, China).

\section{Patient consent for publication}

Not applicable.

\section{Competing interests}

The authors declare that they have no competing interests.

\section{References}

1. Kageyama R and Ohtsuka T: The Notch-Hes pathway in mammalian neural development. Cell Res 9: 179-188, 1999.

2. Radtke F and Raj K: The role of Notch in tumorigenesis: Oncogene or tumour suppressor? Nat Rev Cancer 3: 756-767, 2003.

3. Hatakeyama J, Bessho Y, Katoh K, Ookawara S, Fujioka M, Guillemot F and Kageyama R: Hes genes regulate size, shape and histogenesis of the nervous system by control of the timing of neural stem cell differentiation. Development 131: 5539-5550, 2004.

4. Kageyama R, Ohtsuka T and Tomita K: The bHLH gene Hes1 regulates differentiation of multiple cell types. Mol Cells 10: 1-7, 2000.

5. Nakao K and Campos-Ortega JA: Persistent expression of genes of the enhancer of split complex suppresses neural development in Drosophila. Neuron 16: 275-286, 1996.

6. Sasai Y, Kageyama R, Tagawa Y, Shigemoto R and Nakanishi S: Two mammalian helix-loop-helix factors structurally related to Drosophila hairy and Enhancer of split. Genes Dev 6: 2620-2634, 1992.

7. Ishibashi M, Ang SL, Shiota K, Nakanishi S, Kageyama R and Guillemot F: Targeted disruption of mammalian hairy and Enhancer of split homolog-1 (HES-1) leads to up-regulation of neural helix-loop-helix factors, premature neurogenesis, and severe neural tube defects. Genes Dev 9: 3136-3148, 1995.

8. Bai G, Sheng N, Xie Z, Bian W, Yokota Y, Benezra R, Kageyama R, Guillemot $F$ and Jing N: Id sustains Hes1 expression to inhibit precocious neurogenesis by releasing negative autoregulation of Hes1. Dev Cell 13: 283-297, 2007.

9. Baek JH, Hatakeyama J, Sakamoto S, Ohtsuka T and Kageyama R: Persistent and high levels of Hes1 expression regulate boundary formation in the developing central nervous system. Development 133: 2467-276, 2006.

10. Chapouton P, Webb KJ, Stigloher C, Alunni A, Adolf B, Hesl B, Topp S, Kremmer E and Bally-Cuif L: Expression of hairy/enhancer of split genes in neural progenitors and neurogenesis domains of the adult zebrafish brain. J Comp Neurol 519: 1748-1769, 2011.

11. Wang Y, Chan SL, Miele L, Yao PJ, Mackes J, Ingram DK, Mattson MP and Furukawa K: Involvement of Notch signaling in hippocampal synaptic plasticity. Proc Natl Acad Sci USA 101 9458-9462, 2004.

12. Berezovska O, Xia MQ and Hyman BT: Notch is expressed in adult brain, is coexpressed with presenilin-1, and is altered in Alzheimer disease. J Neuropathol Exp Neurol 57: 738-745, 1998.

13. John GR, Shankar SL, Shafit-Zagardo B, Massimi A, Lee SC, Raine CS and Brosnan CF: Multiple sclerosis: Re-expression of a developmental pathway that restricts oligodendrocyte maturation. Nat Med 8: 1115-1121, 2002.
14. Chirumamilla S, Sun D, Bullock MR and Colello RJ: Traumatic brain injury induced cell proliferation in the adult mammalian central nervous system. J Neurotrauma 19: 693-703, 2002.

15. Richardson RM, Sun D and Bullock MR: Neurogenesis after traumatic brain injury. Neurosurg Clin N Am 18: 169-181, xi, 2007.

16. Yu X, Alder JK, Chun JH, Friedman AD, Heimfeld S, Cheng L and Civin CI: HES1 inhibits cycling of hematopoietic progenitor cells via DNA binding. Stem Cells 24: 876-888, 2006.

17. Sang L, Coller HA and Roberts JM: Control of the reversibility of cellular quiescence by the transcriptional repressor HES1. Science 321: 1095-1100, 2008.

18. Ridet JL, Malhotra SK, Privat A and Gage FH: Reactive astrocytes: Cellular and molecular cues to biological function. Trends Neurosci 20: 570-577, 1997

19. Monje ML, Toda $H$ and Palmer TD: Inflammatory blockade restores adult hippocampal neurogenesis. Science 302: 1760-1765, 2003

20. Prozorovski T, Schulze-Topphoff U, Glumm R, Baumgart J, Schröter F, Ninnemann O, Siegert E, Bendix I, Brüstle O, Nitsch R, et al: Sirt1 contributes critically to the redox-dependent fate of neural progenitors. Nat Cell Biol 10: 385-394, 2008.

21. Thomas CE, Edwards P, Wickham TJ, Castro MG and Lowenstein PR: Adenovirus binding to the coxsackievirus and adenovirus receptor or integrins is not required to elicit brain inflammation but is necessary to transduce specific neural cell types. J Virol 76: 3452-3460, 2002.

22. Einfeld DA, Brough DE, Roelvink PW, Kovesdi I and Wickham TJ: Construction of a pseudoreceptor that mediates transduction by adenoviruses expressing a ligand in fiber or penton base. J Virol 73: 9130-9136, 1999.

23. Kirby I, Davison E, Beavil AJ, Soh CP, Wickham TJ, Roelvink PW, Kovesdi I, Sutton BJ and Santis G: Mutations in the DG loop of adenovirus type 5 fiber knob protein abolish high-affinity binding to its cellular receptor CAR. J Virol 73: 9508-9514, 1999

24. Schmidt A, Böckmann M, Stoll A, Racek T and Pützer BM: Analysis of adenovirus gene transfer into adult neural stem cells. Virus Res 114: 45-53, 2005.

25. Schmidt A, Haas SJ, Hildebrandt S, Scheibe J, Eckhoff B, Racek T, Kempermann G, Wree A and Pützer BM: Selective targeting of adenoviral vectors to neural precursor cells in the hippocampus of adult mice: New prospects for in situ gene therapy. Stem Cells 25: 2910-2918, 2007.

26. Thompson HJ, Lifshitz J, Marklund N, Grady MS, Graham DI, Hovda DA and McIntosh TK: Lateral fluid percussion brain injury: A 15-year review and evaluation. J Neurotrauma 22: 42-75, 2005.

27. Wojtowicz JM and Kee N: BrdU assay for neurogenesis in rodents. Nat Protoc 1: 1399-1405, 2006.

28. Alvarez-Buylla A and Lim DA: For the long run: Maintaining germinal niches in the adult brain. Neuron 41: 683-686, 2004.

29. Lie DC, Song H, Colamarino SA, Ming GL and Gage FH: Neurogenesis in the adult brain: New strategies for central nervous system diseases. Annu Rev Pharmacol Toxicol 44: 399-421, 2004

30. Ramaswamy S, Goings GE, Soderstrom KE, Szele FG and Kozlowski DA: Cellular proliferation and migration following a controlled cortical impact in the mouse. Brain Res 1053: 38-53, 2005.

31. Urrea C, Castellanos DA, Sagen J, Tsoulfas P, Bramlett HM and Dietrich WD: Widespread cellular proliferation and focal neurogenesis after traumatic brain injury in the rat. Restor Neurol Neurosci 25: 65-76, 2007.

32. Kernie SG and Parent JM: Forebrain neurogenesis after focal Ischemic and traumatic brain injury. Neurobiol Dis 37: 267-274, 2010.

33. Richardson RM, Singh A, Sun D, Fillmore HL, Dietrich DW III and Bullock MR: Stem cell biology in traumatic brain injury: Effects of injury and strategies for repair. J Neurosurg 112: $1125-1138,2010$.

34. Ninkovic J and Götz M: Signaling in adult neurogenesis: From stem cell niche to neuronal networks. Curr Opin Neurobiol 17: 338-344, 2007.

35. Suh H, Deng W and Gage FH: Signaling in adult neurogenesis. Annu Rev Cell Dev Biol 25: 253-275, 2009.

36. Anderson WF: Human gene therapy. Nature 392 (6679 Suppl): S25-S30, 1998.

37. Cartmell T, Southgate T, Rees GS, Castro MG, Lowenstein PR and Luheshi GN: Interleukin-1 mediates a rapid inflammatory response after injection of adenoviral vectors into the brain. J Neurosci 19: 1517-1523, 1999. 
38. Thomas CE, Birkett D, Anozie I, Castro MG and Lowenstein PR: Acute direct adenoviral vector cytotoxicity and chronic, but not acute, inflammatory responses correlate with decreased vector-mediated transgene expression in the brain. Mol Ther 3: 36-46, 2001.

39. Lowenstein PR, Mandel RJ, Xiong WD, Kroeger K and Castro MG: Immune responses to adenovirus and adenoassociated vectors used for gene therapy of brain diseases: The role of immunological synapses in understanding the cell biology of neuroimmune interactions. Curr Gene Ther 7: 347-360, 2007.

40. Yan R, Zhang L, Zhang Q, Li J, Kang X, Wang H, Zhang J, Yang S and Yang $\mathrm{X}$ : A new finding concerning adenoviral-mediated gene transfer: A high-level, cell-specific transgene expression in the neural stem cells of adult mice. J Virol Methods 186: 1-6, 2012.

41. Brown JP, Couillard-Després S, Cooper-Kuhn CM, Winkler J, Aigner L and Kuhn HG: Transient expression of doublecortin during adult neurogenesis. J Comp Neurol 467: 1-10, 2003.
42. Yu TS, Zhang G, Liebl DJ and Kernie SG: Traumatic brain injury-induced hippocampal neurogenesis requires activation of early nestin-expressing progenitors. J Neurosci 28: 12901-12912, 2008.

43. Taupin P: BrdU immunohistochemistry for studying adult neurogenesis: Paradigms, pitfalls, limitations, and validation. Brain Res Rev 53: 198-214, 2007.

This work is licensed under a Creative Commons Attribution-NonCommercial-NoDerivatives 4.0 International (CC BY-NC-ND 4.0) License. 